\title{
Demand for Institutional Delivery in Bangladesh: An Application of Household Production Function
}

\author{
Md. Abdus Salam Akanda \\ Department of Statistics, Biostatistics \& Informatics, Dhaka University, Dhaka-1000, Bangladesh \\ E-mail: akanda_du@yahoo.com
}

Received on 01. 03.2011. Accepted for Publication on 08. 10. 2011

\begin{abstract}
Maternal and child health issues continue to be at the forefront of national and global health policies. Notwithstanding the national and global policy initiatives, maternal mortality continues to be on the ascendancy in developing countries. This paper investigates the determinants of institutional delivery among a cross section of Bangladeshi women. For appropriate policy targeting, it is imperative to investigate the factors that promote institutional delivery and those that retard it. Using discrete choice model, and controlling for other covariates, we found that, women from the richest income quintile, and those that have access to health information via television delivered at appropriate health institutions. Besides, place of residence, mother's education, wanted pregnancy, utilization of antenatal care services and number of health worker's visiting time inter alia were found to be significant predictors of the demand for institutional and supervised delivery. The policy implication of this finding is that health education via television is more effective than print media. Secondly, government policies meant to create jobs and increase income levels are envisaged as proper policy instrument to induce the utilization of appropriate health services including institutional delivery. Thirdly, information, education and communication (IEC) programs are urgently needed to inform women about the cause and potential risk of maternal health complications as well as the significance of institutional delivery. Finally, the use of health inputs such as antenatal care during pregnancy should be encouraged.
\end{abstract}

Keywords: Expectant Mothers, Institutional delivery, Income Quintile, Health Information, Bangladesh

\section{Introduction}

Health is universally regarded as an important index of human development. Improvements in health would translate into higher incomes, higher economic growth, and accelerated declines of poverty. Maternal health refers to the health of women during pregnancy, childbirth and the postpartum period. While motherhood is often a positive and fulfilling experience, for too many women it is associated with suffering, ill-health and even death. Early and regular check-ups by health professionals are essential in assessing the physical status of women during pregnancy and ensuring appropriate interventions during delivery. In spite of the national and global effort at curbing maternal morbidity and mortality, through the safe motherhood initiative, the phenomenon is on the ascendancy in many developing countries (Weil and Fernandez, 1999). Worldwide, over 500,000 women and girls die of complications related to pregnancy and childbirth each year. Over 99 percent of those deaths occur in developing countries such as Bangladesh. For every woman or girl who dies as a result of pregnancy-related causes, between 20 and 30 more will develop short- and long-term disabilities, such as obstetric fistula, a ruptured uterus, or pelvic inflammatory disease. Bangladesh's maternal mortality rate continues at an unacceptably high level. While maternal mortality figures vary widely by source and are highly controversial, the best estimates for Bangladesh suggest that approximately 25,800 women and girls die each year due to pregnancy related complications. Additionally, another 516,000 to 774,000 Bangladeshi women and girls will suffer from disabilities caused by complications during pregnancy and childbirth each year (Hill et. al., 2001). Interestingly, a large proportion of these deaths could be prevented through timely and appropriate interventions such as antenatal care, delivery and postnatal care (Royston and Armstrong, 1989). Women play a major role in the rearing of children and the management of family affairs, hence, their loss from delivery complications is a significant social and personal tragedy.
It is often maintained that women's choices and preferences for location of childbirth are enshrined in society's understanding of birth as a social process. In the developed world, this conception is based on biomedical knowledge coupled with two competing models of child birth; the biomedical/technocratic model and natural/holistic model, mediating women's choices and preferences for child birth location (Viisainen, 2001). In contrast, the developing world offers a varied picture, ranging from reluctance to use biomedical services even in cases of pregnancy-related complications, given women's penchant to have normal home births surrounded by their families (Berry, 2006). Undoubtedly, the choice of and preference for childbirth location are influenced by the socio-economic factors of the contextual environment in which they arise. Cultural and religious epistemologies shape the demand for health seeking such as the demand for delivery institution. In some communities, it is regarded a bad omen if a woman delivers via caesarian section, hence the choice of home delivery.

Traditionally, children in Bangladesh are delivered at home with the assistance of birth attendants or elderly women of the community (BDHS, 2009). An important component of efforts to reduce the health risks of mothers and children is to increase the proportion of babies delivered under medical supervision. The level of assistance a woman receives during the birth of her child has important health consequences for both mother and child. Births delivered at home are more likely to be delivered without professional assistance, whereas births delivered at a health facility are delivered by trained medical personnel. Medically assisted deliveries are still low in Bangladesh, with less than $20 \%$ benefiting from professional delivery assistance over the past 15 years (BDHS, 2009). Home delivery mostly prolongs labor and is a recipe for Obstetric Fistula.

For definitional purposes, institutional/supervised delivery as used in this paper is any delivery that occurred in a modern health facility and was assisted by medically trained professionals such as medical doctors, nurses and 
midwife/auxiliary midwife. Data from the Bangladesh Demographic and Health Survey 2007 show that $80 \%$ of the deliveries still take place at home. The percentage of deliveries with assistance from qualified professionals is also very low, $18 \%$ deliveries are attended by medically trained personnel while $10.8 \%$ births are attained by trained birth attendants. Only $15 \%$ births take place at health facility (BDHS, 2009). Although maternal health care utilization is essential for further improvement of maternal and child health little is known about the current magnitude of use and factors influencing the use of these services in Bangladesh. This paper therefore aims to fill this gap by using the data of Bangladesh Demographic and Health Survey, 2007.

The principal objective of this paper is to investigate the factors influencing the demand for institutional delivery, particularly household income and media. Thus we test the hypothesis that income and media have no significant effect on the demand for institutional delivery. It is envisaged that the results of the study will improve policymakers' understanding of the determinants of institutional delivery in the country and serve as an important tool for any possible intervention aimed at improving the low utilization of maternity care services in the country.

\section{Conceptual Framework}

In the health care demand literature; individual, household and provider characteristics have often been found to be empirically associated with the demand for health care (Akanda and Minowa, 2011). The role of human capital in health seeking has gained prominence over the past few decades (Grossman 1972, 1999). Education for instance, both own and parental has received widespread empirical attention, showing a positive association with the demand for health care (Currie et. al., 2003).

Household decision-making processes and intra-household allocation of health resources have also been examined in the empirical literature. Following Becker's (1981) seminal paper, unitary utility function household models have been challenged on the grounds that husband and wife may have different preference sets, particularly in relation to health and health care. Thus the consumption of health inputs is seen as the result of a bargaining process (Beegle et. al., 2001; Maitra, 2004). In this case, the couple undertakes negotiation to make the decision conditional on their preferences. The outcome of this bargaining process depends essentially on the distribution of power within the couple. Empirical evidence shows that women with little power in household decisions demand less health services (Thomas et. al., 1997; Maitra, 2004). On the other hand, a woman with more power relative to her husband, demand more prenatal visits and professional delivery services.

In most developing countries, access to safe motherhood services in rural areas is more limited than in urban areas. This issue is of particular significance for Bangladesh since nearly 80 percent of its population lives in rural areas where poor road networks make health care accessibility problematic and where the private providers of health care rarely provide health services. The poor geography of such places makes it difficult for government health services to be easily reachable. In this paper, the place of residence; being rural or urban is used to capture geographical differences. Chandra and Skinner (2003) examined the unequal geographic distribution of quality care as a source of both health care and health disparities. The Government of Bangladesh (GOB) is trying to give the family planning facilities for all people including rural areas of Bangladesh to ensure basic health services for the grassroots people. For this purpose GOB is setting up clinic for a day or part of a day in the village or mohalla. Also family planning workers visit home to talk about family planning or to give family planning methods and let people know about available services and care.

The basic framework that guides this paper is a household production function. The behavior of the household is such that parents maximize a household welfare function $(W)$. Each parent has a separate utility function which depends on the consumption of goods purchased in the market $(X)$, the consumption of leisure $(h)$, observable and unobservable characteristics of the parents and the household ( $\mathrm{Z}$ ) that may influence tastes and preferences, and through this channel, their levels of utility and the well being indicators of household members (M).

The individual utility functions can be expressed as follows;

$$
U^{i}=U^{i}(X, h, M, Z), i=m, f
$$

Where $U^{m}$ denotes the utility of the mother $(m)$ and $U^{f}$ denotes the utility of the father $(f)$. Although $M$ can designate the well being of all of households, in this paper, we restrict it to include only the health of the expectant mother and indirectly the health of the unborn child since the choice of delivery institution can affect the health of both the mother and the child. Within this framework parents may have different preferences for the consumption of goods, leisure, and human capital and also value differently the well-being and consumption of the other members of the household. Parents choose $X, h, M$ to maximize the household welfare function (W), which aggregates their individual utility functions:

$$
w=w\left(U^{m}(X, h, M, Z), U^{f}(X, h, M, Z)\right)
$$

Households face two constraints:

$$
\begin{aligned}
& M=M(D, P, H, C) \\
& w_{m}\left(T_{m}-h_{m}\right)+w_{f}\left(T_{f}-h_{f}\right)+I_{m}+I_{f}=X+p D
\end{aligned}
$$

Equation (3) represents a restriction imposed by the health production function. Parents cannot purchase health stock $(M)$ in the market, so they have to produce it. The amount of health produced is determined by health care inputs $(D)$, such as prenatal care and choice of delivery institution, characteristics of the parents $(P)$, the household $(H)$ and the community $(C)$ that affect the productivity with which inputs can be transformed into outputs. Equation (4) 
represents the budget constraint of the household. It expresses the simultaneous determination of parents' time allocation and household earnings. Here, ' $w_{i}$ ' is the wage, ' $T_{i}$ ' is the time endowment for the parents, $\left(\mathrm{T}_{\mathrm{i}}-\mathrm{h}_{\mathrm{i}}\right)$ is the time allocated to work and ' $I_{i}$ ' is the unearned income of each parent. The right hand of the equation represents the consumption of goods purchased in the market $(X)$ plus expenditure on health inputs $(p D)$ where ' $\mathrm{p}$ ' is the price of health inputs. Household's total expenditure cannot exceed total income.

Hence the demand for health care (D) is such that:

$$
D=D(P, R, H, C, p)
$$

Where ' $P$ ' is a vector of the mother's characteristics while father's characteristics are incorporated through bargaining result variables, such as who heads the household or makes decisions over family planning (in this paper, the bargaining power is captured by a dummy for women headed households). ' $R$ ' is the residence of the mother (rural or urban). Vector ' $H$ ' represents characteristics of the household. Vector ' $C$ ' represents community characteristics such as 'setting up any clinic for a day or part of a day in the village or mohalla' and 'number of health worker's visiting time to talk about family planning or to give family planning methods'. Finally, ' $p$ ' is an indicator of the expectant mothers' health seeking behavior which is captured by the mother's education.

\section{Econometric Specification}

The econometric estimation is based on the extensively applied binary choice model, the logit, where the parameters are estimated using maximum likelihood procedures (Wooldridge, 2009). We assume the existence of a binary variable $y_{i j}$ that takes the value of 1 if expectant mother $i$ chooses institutional delivery (indexed as alternative $j=1$ ) and 0 otherwise (indexed as alternative $j=0$ ).

Thus, $y_{i j}=1$ if $j=1$ (institutional delivery)

$$
y_{i j}=0 \text { if } j=0 \text { (otherwise) }
$$

Writing the probability that expectant mother i opts for alternative 1 as, $P_{i l}=\operatorname{Pr}\left[y_{i l}=1\right]$, then,

$$
\sum_{j=0}^{1} P_{i l}=\sum_{j=0}^{1} y_{i j}=1
$$

Assuming a sample of $n$ expectant mothers, the likelihood function is given by;

$$
l=\prod_{i=1}^{n} P_{i 0}^{y_{i 0}} P_{i 1}^{y_{i 1}}
$$

Taking logs on (1.2), we arrive at the following loglikelihood function

$$
\ln l=\sum_{i=1}^{n}\left(y_{i 0} \ln P_{i 0}+y_{i 1} \ln P_{i 1}\right)
$$

The model behind (1.3) can be changed into a behavioral one by relating the selection probabilities to attributes of the alternatives in the choice set and the attributes of the expectant mother making the choice. The model can be motivated by assuming that individuals maximize utility and that the utility function is stochastic; that is, a random utility model (McFadden 1981). The stochastic nature of the utility function emerges from the assumption that consumers are rational in that they make choices that maximize their perceived utility subject to constraints on expenditures (Maddala, 1983).

Assuming linearity and denoting $U_{i 0}$ and $U_{i 1}$ as the utility derived by expectant mother $i$ from utilizing noninstitutional and institutional deliveries respectively; $x_{i}$ a vector of individual's attributes, and $z_{i 0}, z_{i 1}$ vectors of providers' attributes as perceived by expectant mother $i$, we can write;

$$
\begin{aligned}
& U_{i 0}=\alpha_{0}+x_{i}^{\prime} \delta_{0}+Z_{i 0}^{\prime} \gamma+e_{i 0} \\
& U_{i 1}=\alpha_{1}+x_{i}^{\prime} \delta_{1}+Z_{i 1}^{\prime} \gamma+e_{i 1}
\end{aligned}
$$

The observed choice between (1.4) and (1.5) discloses which alternative provides the greater utility, but not the unobservable utilities. The demand function for a particular alternative is the probability that the utility derived from it is higher than the utility derived from the other. Thus, the observed indicator $y_{i j}=1$ if $U_{i l}>U_{i 0}$, and the observed indicator $y_{i j}=0$ if $U_{i l}<U_{i 0}$. Therefore the probability that $\mathrm{y}_{\mathrm{ij}}$ be equal to 1 is given by the expression,

$$
\begin{aligned}
& \operatorname{Pr}\left(y_{i j}=1\right)=\operatorname{Pr}\left(U_{i 1}>U_{i 0}\right) \\
& =\operatorname{Pr}\left[\left(e_{i 1}-e_{i 0}\right)<\left(\alpha_{1}-\alpha_{0}\right)+x_{i}^{\prime}\left(\delta_{1}-\delta_{0}\right)+\left(Z_{i 1}-Z_{i 0}\right)^{\prime} \gamma\right] \\
& =F\left(w_{i}^{\prime} \beta\right)
\end{aligned}
$$

where $F$ represent the cumulative distribution function for the error term $e_{i}$, and with

$$
w_{i}=\left[1, x_{i},\left(Z_{i 1}-Z_{i 0}\right)^{\prime}\right], \beta^{\prime}=\left[\left(\alpha_{1}-\alpha_{0}\right),\left(\delta_{1}-\delta_{0}\right)^{\prime}, \gamma^{\prime}\right]
$$

The logit model is based on the assumption that the cumulative distribution function of $e_{i}$ is the logistic. Then, the probability that $y_{i j}=1$ is expressed as;

$$
\operatorname{Pr}\left(y_{i j}=1\right)=\frac{\exp \left(w_{i}^{\prime} \beta\right)}{1+\exp \left(w_{i}^{\prime} \beta\right)}
$$

In equations (1.4) and (1.5), the coefficients of vector $x_{i}$ were allowed to vary between alternatives. Since only differences in utility matter, if any explanatory variable is equal between alternatives, it will not influence individual choice. This implies that the variable in question does not contribute to the explanation of why one particular alternative is chosen and its coefficient can not be estimated. Hence, if the coefficients of those variables reflecting individuals' attributes, which do not change between alternatives, are to be identified, they must be allowed to have differential impacts upon the probability of choosing one alternative over the other. In order words, the coefficients must be made alternative-specific. 


\section{Sampling Design and Data}

The data utilize for this study extracted from Bangladesh Demographic and Health Survey conducted over a five month period from 24 March to 11 August 2007 under the authority of the National Institute for Population Research and Training (NIPORT) of the ministry of Health and Family Welfare, Bangladesh. It was implemented by Mitra and Associates, a Bangladeshi research firm located in Dhaka. Technical assistance was provided by Macro International Inc., a private research firm located in Calverton, Maryland, USA, through the MEASURE DHS program. Financial support for the survey was provided by the U.S. Agency for International Development (USAID/Bangladesh). The 2007 Bangladesh Demographic and Health Survey (2007 BDHS) is a nationally representative survey of 10,996 women aged 15-49 and 3,771 men aged 15-54 from 10,400 households covering 361 sample units (clusters/PSUs) throughout Bangladesh, 134 in urban areas and 227 in rural areas. The survey is based on a two-stage stratified sample household. At the first stage of sampling, 361 Primary Sampling Units (PSUs) were selected. The selection of PSUs was done independently for each stratum and with probability proportion to PSU size, in terms of number of households. At the second stage of sampling, on average, 30 households were selected from each PSU, using an equal probability systematic sampling technique. Details of the sampling design are provided in the main BDHS report (BDHS, 2009). The survey collected household information as well as individual characteristics of the women, including a complete birth history and information on contraceptive use. Data on antenatal, delivery and postnatal care, vaccinations, and the nutritional status of children were also collected. Since this study focuses on women's institutional delivery issues, so a sub-data set is set up from the full data set only for the expectant mothers. Finally the sub-data set hold the information of 4925 expectant mothers including their individual, household, economical and environmental characteristics.

\section{Descriptive Statistics}

The general characteristics of the sample are presented in Table 1. The sample BDHS data show that most deliveries still occur at respondent's home and are attended by medically unskilled birth attendants. Among all live births and stillbirths in the three years preceding the survey, $81.18 \%$ occurred outside appropriate health institutions with no supervision while $18.82 \%$ of the deliveries took place in health institutions supervised by medical personnel. Respondent's home delivery accounted for the highest $(58.76 \%)$ with 'NGO clinic' being the least (1.34\%). $8.63 \%$ of facility-based deliveries occurred at a government hospital, upazila (administrative unit) health complex, or maternal and child welfare center, $8.85 \%$ at a private hospital or clinic, and $22.42 \%$ at other places.

Table. 1. Descriptive Statistics of the Explanatory Variables (Institutional and Non-institutional Delivery)

\begin{tabular}{|c|c|c|c|}
\hline Variable & Inst. Del Mean (SD) & Non-Inst. Del Mean (SD) & Total Mean (SD) \\
\hline Mother's age & $25.78(5.83)$ & $25.89(6.45)$ & $25.87(6.34)$ \\
\hline Mother's age square & $698.37(322.32)$ & $712.10(367.40)$ & $709.52(359.36)$ \\
\hline Mother's education (Years) & $8.47(3.71)$ & $3.82(3.49)$ & $4.69(3.97)$ \\
\hline Woman watches television & $0.82(0.39)$ & $0.48(0.50)$ & $0.55(0.50)$ \\
\hline Woman reads newspaper & $0.40(0.49)$ & $0.11(0.31)$ & $0.16(0.37)$ \\
\hline Woman listens to radio & $0.24(0.43)$ & $0.23(0.42)$ & $0.23(0.42)$ \\
\hline Women belongs to NGO & $0.26(0.44)$ & $0.39(0.49)$ & $0.37(0.48)$ \\
\hline Wanted pregnancy $($ yes $=1)$ & $0.02(0.13)$ & $0.04(0.19)$ & $0.03(0.18)$ \\
\hline First order birth $($ yes $=1)$ & $0.51(0.50)$ & $0.27(0.44)$ & $0.31(0.46)$ \\
\hline Birth order $5+($ yes $=1)$ & $0.013(0.11)$ & $0.09(0.29)$ & $0.08(0.27)$ \\
\hline Antenatal care $(1-2)($ yes $=1)$ & $0.16(0.37)$ & $0.31(0.46)$ & $0.28(0.45)$ \\
\hline Antenatal care $(3-4)($ yes $=1)$ & $0.25(0.43)$ & $0.16(0.37)$ & $0.17(0.38)$ \\
\hline Antenatal care $4+($ yes $=1)$ & $0.52(0.50)$ & $0.09(0.28)$ & $0.17(0.37)$ \\
\hline 2nd income quintile & $0.06(0.23)$ & $0.23(0.42)$ & $0.20(0.40)$ \\
\hline 3rd income quintile & $0.09(0.29)$ & $0.21(0.40)$ & $0.19(0.39)$ \\
\hline 4th income quintile & $0.20(0.40)$ & $0.19(0.39)$ & $0.19(0.39)$ \\
\hline Richest income quintile & $0.60(0.49)$ & $0.15(0.36)$ & $0.23(0.42)$ \\
\hline Household size & $6.54(3.41)$ & $6.26(3.04)$ & $6.32(3.12)$ \\
\hline Household head $($ woman $=1)$ & $0.11(0.32)$ & $0.09(0.29)$ & $0.10(0.30)$ \\
\hline Place of residence (rural $=1$ ) & $0.38(0.49)$ & $0.71(0.46)$ & $0.65(0.48)$ \\
\hline $\begin{array}{l}\text { Setting up any clinic for a day or part of a } \\
\text { day in the village or mohalla }\end{array}$ & $0.63(0.48)$ & $0.72(0.45)$ & $0.70(0.46)$ \\
\hline $\begin{array}{l}\text { Number of health worker's visiting time to } \\
\text { talk about family planning or to give family } \\
\text { planning methods }\end{array}$ & $0.48(1.18)$ & $0.63(1.46)$ & $0.60(1.41)$ \\
\hline Number of observations & 927 & 3998 & 4925 \\
\hline
\end{tabular}




\section{Empirical Results and Discussion}

Table 2 presents the key variables under consideration without control variables. Odds ratio is the ratio of the probability of occurrence of an event to the probability of the event not occurring. This is often estimated by the ratio of the number of times that the event of interest occurs to the number of times that it does not. The marginal effects were computed at their means for the continuous independent variables. For the binary variables, however, the marginal effects were calculated as the discrete change in the independent variable form 0 to 1 . The estimation is done by the powerful statistical software stata 11 (Stata, 2010). It is evident that income and access to health information (media) are key determinants of the demand for health services by expectant mothers; in this case institutional delivery. Women from households in the intermediate and higher income quintiles are more likely to give birth in appropriate health institutions and under supervision. Women from households within the highest income quintile are more likely to demand institutional delivery by 36 percentage points as compared to their counterparts in the lowest income quintile. In terms of odds ratio, women from households within the highest income quintile are 8.56 times more likely to demand institutional delivery than women from the poorest income quintile when all other independent variables remains fixed. In Brazil,
Béhague et al (2002) found that women from families with higher incomes and higher levels of education had caesarian sections more often than other women. Steinhardt (2008) also found significant relationship between higher income and utilization of health services. However, the robustness of the income variables is in variance with that of Mpembeni et al. (2007) where socio-economic status had no significant statistical relationship with skilled attendance at delivery.

In terms of access to media or health information, women who access health information via television are more likely to increase institutional delivery by 7 percentage points. In terms of odds ratio, women who watch television are 1.81 times more likely to demand institutional delivery than the women who do not watch television when all other independent variables remains fixed. While women who read Newspapers are more likely to increase institutional delivery by 15 percentage points, access to radio is inversely related to the phenomenon. Islam et al. (2009) in a study on Bangladeshi women found that television was the most significant form of mass media to disseminate family planning messages.

Table. 2. Logit Estimates for Demand for Institutional Delivery (Without Controls)

\begin{tabular}{lccrr}
\hline Variable & Coefficient & Rob. Std. Err. & Odds Ratio & Marginal Effects \\
\hline $\begin{array}{l}\text { Income } \\
\quad \text { Poorest income quintile (Ref. Cat.) }\end{array}$ & & & & \\
$\quad$ 2nd income quintile & -0.1457 & 0.2083 & 0.8644 & -0.0161 \\
$\quad$ 3rd income quintile & $0.4145^{* * *}$ & 0.1890 & 1.5136 & 0.0519 \\
$\quad$ 4th income quintile & $1.0437^{* * *}$ & 0.1781 & 2.8396 & 0.1496 \\
$\quad$ Richest income quintile & $2.1465^{* * *}$ & 0.1714 & 8.5551 & 0.3549 \\
Health Information & $0.5909^{* * *}$ & & \\
$\quad$ Woman watches television & $1.0385^{* * *}$ & 0.1076 & 1.8055 & 0.0662 \\
$\quad$ Woman reads newspaper & -0.1414 & 0.0946 & 2.8249 & 0.1515 \\
$\quad$ Woman listens to radio & $-3.1004^{* * *}$ & 0.0979 & 0.8682 & -0.0156 \\
Constant & & 0.1525 & & \\
\hline
\end{tabular}

Log Pseudo likelihood = -1864.2529

Number of observations $=4925$

LR $\operatorname{chi} 2(7)=1035.31$

Prob $>$ chi $2=0.0000$

Pseudo R2 $=0.2173$

Hosmer-Lemeshow chi2(8) $=5.44$

Prob $>$ chi $2=0.7094$

Note: $* * *$ Significant at $1 \%$, ** Significant at $5 \%$ and $*$ Significant at $10 \%$.

The main model with the inclusion of control variables has a Pseudo R2 of 0.36 with a Chi2 significant at $1 \%$, all indicating a good model fit. Hosmer-Lemeshow goodnessof-fit test is also representing the same indication (HosmerLemeshow, 2000). After controlling for variety of economic, demographic and provider characteristics, this study finds compelling evidence that income and access to health information increase the probability of institutional delivery. In particular, women who have access to health information via Television are expected to increase their stock of health knowledge. Control variables such as mother's education, wanted pregnancy, place of residence, first order births, birth order5+, and the number of antenatal care attended are significant predictors of the demand for institutional and supervised delivery.

Surprisingly, supply side variables such as setting up any clinic for a day or part of a day in the village or mohalla 
were insignificant in explaining the phenomenon but number of health worker's visiting time to talk about family planning or to give family planning methods had the expected negative significant association with institutional delivery. Mother's education had the expected positive association with institutional delivery and proved significant. This is in sharp contrast with the robust finding that the level of maternal education is significantly related to health care utilization during pregnancy (Chakraborty, et al. 2003; Khanam and Akanda, 2007). This may be the fact that, in rural areas of Bangladesh most of the women are illiterate and their economic status is very low. Their perception is that they are taking safe treatment for delivery from family planning workers and do not feel the demand of institutional delivery.

Table. 3. Logit Estimates for Demand for Institutional Delivery

\begin{tabular}{|c|c|c|c|c|}
\hline Variables & Coefficient & Rob. Std. Err. & Odds Ratio & Marginal Effects \\
\hline Mothers' age & 0.0986 & 0.0662 & 1.1037 & 0.0086 \\
\hline Mother's age square & -0.0009 & 0.0012 & 0.9992 & -0.0001 \\
\hline Mother's education (years) & $0.1780^{* * *}$ & 0.0165 & 1.1948 & 0.0155 \\
\hline Woman watches television & $0.2523^{* * *}$ & 0.1205 & 1.2870 & 0.0218 \\
\hline Woman reads newspaper & 0.0571 & 0.1170 & 1.0588 & 0.0051 \\
\hline Woman listens to radio & -0.0225 & 0.1095 & 0.9778 & -0.0020 \\
\hline Women belongs to NGO & -0.0780 & 0.1055 & 0.9250 & -0.0067 \\
\hline Wanted pregnancy $($ yes $=1$ ) & $-0.6650^{* *}$ & 0.3138 & 0.5143 & -0.0453 \\
\hline First order birth $($ yes $=1)$ & $0.8241^{* * *}$ & 0.1259 & 2.2799 & 0.0821 \\
\hline Birth order $5+($ yes $=1)$ & $-0.7178^{* *}$ & 0.3496 & 0.4878 & -0.0493 \\
\hline Antenatal care $(1-2)($ yes $=1)$ & $0.5958^{* * *}$ & 0.1616 & 1.8145 & 0.0581 \\
\hline Antenatal care $(3-4)($ yes $=1)$ & $1.2795^{* * * *}$ & 0.1618 & 3.5948 & 0.1563 \\
\hline Antenatal care $4+($ yes $=1)$ & $2.1958^{* * *}$ & 0.1627 & 8.9869 & 0.3300 \\
\hline 2nd income quintile & $-0.4255^{*}$ & 0.2182 & 0.6535 & -0.0336 \\
\hline 3rd income quintile & -0.1171 & 0.2019 & 0.8895 & -0.0100 \\
\hline 4th income quintile & 0.0461 & 0.1976 & 1.0472 & 0.0041 \\
\hline Richest income quintile & $0.5881^{* * * *}$ & 0.2069 & 1.8005 & 0.0584 \\
\hline Household size & -0.0076 & 0.0146 & 0.9924 & -0.0007 \\
\hline Household head (woman $=1)$ & -0.1245 & 0.1510 & 0.8830 & -0.0104 \\
\hline Place of residence (rural $=1$ ) & $-0.4231^{* * *}$ & 0.1089 & 0.6550 & -0.0389 \\
\hline $\begin{array}{l}\text { Setting up any clinic for a day or part of a } \\
\text { day in the village or mohalla }\end{array}$ & 0.1289 & 0.1026 & 1.1376 & 0.0110 \\
\hline $\begin{array}{l}\text { Number of health worker's visiting time to } \\
\text { talk about family planning or to give family } \\
\text { planning methods }\end{array}$ & $-0.0924^{* *}$ & 0.0360 & 0.9117 & -0.0081 \\
\hline Constant & -6.4813 & 1.0112 & & \\
\hline $\begin{array}{r}\text { Log Pseudo likelihood }=-1523.6795 \\
\text { Number of observations }=4925 \\
\text { LR chi2 }(22)=1716.46 \\
\text { Prob }>\text { chi } 2=0.0000 \\
\text { Pseudo R2 }=0.3603\end{array}$ & & & & \\
\hline $\begin{array}{r}\text { Hosmer-Lemeshow chi2 }(8)=5.12 \\
\text { Prob }>\text { chi } 2=0.7449\end{array}$ & & & & \\
\hline
\end{tabular}

\section{Summary and Concluding Remarks}

The paper investigated the demand for institutional delivery among a cross section of Bangladeshi expectant mothers. We find compelling evidence that income and access to health information with or without controls are significant in explaining the utilization of maternal health services institutional and supervised delivery. Mother's education had the correct positive sign; its effect on institutional delivery was significant. The policy implication of this finding is that health education via television in local/indigenous languages is more effective than print media. This is corroborated by the fact that the Literacy Assessment Survery 2008 found overall literay rate 49.4\% for population over 11 years and over. High literacy rate in Bangladesh is essential to improve health status. Information, education and communication (IEC) programs are urgently needed to inform women about the cause and potential risk of maternal health complications as well as the significance of institutional delivery. Additionally, government policies to enhance income levels through job creation are envisaged as proper policy instrument to induce the utilization of appropriate health services including institutional delivery. Thus as households move from the lowest income quintile to the intermediate and highest quintiles, more appropriate health services will be demanded. Thirdly, given that rural women are less likely to use institutional delivery services, it is recommended that maternal health care programs should be expanded and intensified in rural areas along with culturally appropriate education campaigns. Furthermore, the use of health inputs such as antennal care during pregnancy should be encouraged. The results indicate that 
women who have sought the WHO recommended antenatal care of at least 4 times were more likely to deliver in appropriate health institutions by 33 percentage points. Finally, the harmful impact of culture and tradition on the use of maternal health services warrant that research be conducted into aspects of traditional religion that discourage the use of such health services.

1) Akanda, M.A.S., and M. Minowa, 2011. Household Demand for Health Care and Health Care Expenditure by Controlling Endogeneity Bias in Bangladesh. Dhaka Univ. J. Sci., 59(1), 137-46.

2) BDHS, 2009. Bangladesh Demographic and Health Survey 2007. Dhaka, Bangladesh and Calverton, Maryland, USA: National Institute of Population Research and Training (NIPORT), Mitra and Associates, and Macro International Inc.

3) Beegle, K., E. Frankenberg and D. Thomas, 2001. Bargaining Power within Couples and Use of Prenatal and Delivery Care in Indonesia. Studies in Family Planning, 32(2), 130-146.

4) Becker, G., 1981. A treatise on the Family. Cambridge: Harvard University Press.

5) Béhague, D.P., C.G. Victora, F.C. Barros, 2002. Consumer Demand for Caesarean Sections in Brazil: Informed Decision Making, Patient Choice, or Social Inequality? A population Based Birth Cohort Study Linking Ethnographic and Epidemiological Methods. BMJ, 324 (7343), 942-5.

6) Berry, N. S., 2006. Kaqchikel Midwifes, Home Births, and Emergency Obstetric Referral in Guatemala: Contextualizing the Choice to Stay at Home. Social Science and Medicine, 62(8), 1958-69.

7) Chakraborty, N. et. al., 2003. Determinants of the use of Maternal Health Services in Rural Bangladesh. Health Promotion International, 18(4), 327-337.

8) Chandra, A. and J. Skinner, 2003. Geography and Racial Health Disparities. NBER Working Paper No. 9513

9) Currie, J. and E. Morreti, 2003. Mother's Education and the Intergenerational Transmission of Human Capital: Evidence from College Openings. Quarterly Journal of Economics, 118 (4), 1495-1532.

10) Grossman, M., 1972. On the concept of Human Capital and the Demand for Health. Journal of Political Economy, 80(2), 223-235.
11) Grossman, M., 1999. The Human Capital Model of the Demand for Health. NBER Working Papers 7078.

12) Hill, K., C. AbouZahr, and T. Wardlaw, 2001. Estimates of Maternal Mortality for 1995. Bulletin of the World Health Organization, 79 (3), 182-193.

13) Hosmer, D. W. and S. Lemeshow, 2000. Applied logistic regression. John Wiley, New York.

14) Islam, M. R., M. A. Islam, and B. Banowary, 2009. Determinant of Exposure to Mass Media Family Planning Messages among Indigenous People in Bangladesh: A study on the Garo. Journal of Biosocial Science, 41(2), 221-229.

15) Khanam, M. and M. A. S. Akanda, 2007. Determinants of Delivery Complications in Rural Bangladesh. Journal of Applied Sciences Research, 3(11), 1320-1326.

16) Maddala, G. S., 1983. Limited-Dependent and Quantitative Variables in Econometrics, Cambridge, Cambridge University Press.

17) Maitra, P., 2004. Parental Bargaining, Health Inputs and Child Mortality in India. Journal of Health Economics, 23(2), 259291.

18) McFadden, D. 1981. Econometric Models of Probabilistic Choice, in C. M anski and D. McFadden (eds), Structural Analysis of Discrete Data: With Econometric Applications. Cambridge, Mass.: M.I.T. Press.

19) Mpembeni, R. N. M. et. al., 2007. Use Pattern of Maternal Health Servicies and Determinants of Skilled Care during Delivery in Southern Tanzania: Implications for Achievement of MDG-5 targets. BMC Pregnancy and Childbirth, 7, 29.

20) Royston, E., and S. Armstrong, 1989. Preventing Maternal Deaths, Geneva: WHO.

21) Stata Corp LP, 2010. Data Analysis and Statistical Software (Stata): Release 11.0. College Station, Texas, USA.

22) Thomas, D., D. Contreras and E. Frankenberg, 1997. Distribution of Power within the Household and Child Health, Santa Monica, CA: RAND.

23) Weil, O. and H. Fernandez, 1999. Is Safe Motherhood an Orphan Initiative? Lancet, 354(9182), 940-43.

24) Wooldridge, J. M., 2009. Introductory Econometrics: A Modern Approach, 4th Edition, Manson, Ohio: Thomson South Western.

25) Viisainen, K., 2001. Negotiating Control and Meaning: Home Birth as a Self- Constructed Choice in Finland. Social Science and Medicine, 52(7), 1109-21. 